\section{Growing a PEG-like alternative}

\section{By Kai-Jye Lou, Staff Writer}

Researchers at Duke University are developing a drug delivery technology that is designed to circumvent potential size limitations and manufacturing difficulties associated with pegylation. ${ }^{1}$ The technology still needs to be tested head-to-head versus pegylation.

Pegylation involves attaching a polyethylene glycol (PEG) molecule to a protein or peptide. PEG molecules can reduce protein degradability, immunogenicity and elimination, and thus increase circulating half-life. However, controlling and tailoring pegylation reactions can be complicated and laborious for many proteins. ${ }^{2}$

The approach is hard to standardize, as the unique chemical and structural properties of each protein can impose restrictions on the placement and length of PEG molecules. Increasing the size of the polymer chain will increase a protein's half-life, but larger chains are usually more difficult to attach.

There also is a trade-off between increased PEG size and reduced biological activity. Finally, the reaction process or protein often needs to be modified to prevent unwanted interactions between the PEG molecules and certain amino acids.

The Duke team opted for a different approach: start small, have a single reaction site and use a different polymer. They modified the $\mathrm{N}$-terminus of a protein and attached a small molecule that initiates the polymerization reaction. The modified terminus becomes the only location on the protein that can initiate the controlled growth of a poly(oligo(ethylene glycol) methyl ether methacrylate) (poly[OEGMA]) chain.

As proof of concept, the group generated poly[OEGMA]-conjugated myoglobin. In mice, the modified myoglobin showed a 41 -fold increase in blood exposure compared with unconjugated myoglobin. The modified myoglobin had an elimination half-life of 18 hours compared with 2 hours for the unconjugated form.

The findings were published in the Proceedings of the National Academy of Sciences.

"We have introduced a novel, general and efficient approach to grow a new therapeutically useful polymer architecture directly from only one universal site on a protein to form polymer conjugates with high yield and good retention of protein activity," said corresponding author Ashutosh Chilkoti. "We believe that this new approach to the synthesis of $\mathrm{N}$-terminal protein conjugates of poly[OEGMA] may be applicable to a large subset of protein and peptide drugs and thereby provide a general methodology for improvement of their pharmacological profiles."

Chilkoti is director of the Center for Biologically Inspired Materials and Materials Systems and a professor of biomedical engineering at Duke.

"From a synthetic point of view, the method is very powerful: it is much easier to grow a very long polymer on a protein than it is to attach a preformed one," said Jeffrey Hubbell, professor of bioengineering and chemical engineering and director of the Institute for Bioengineering at The Swiss Federal Institute of Technology.

\section{The poly[OEGMA] advantage}

The yield rate for attaching an initiator molecule to myoglobin was about $75 \%$. As a comparison, Chilkoti noted that the yield for proteins conjugated to other polymers, including PEG, could be as low as $10 \%-20 \%$. He added that his group's $\mathrm{N}$-terminal poly[OEGMA] conjugation approach should be scalable and able to achieve synthesis speeds comparable to those for pegylation reactions.

poly[OEGMA]-conjugated myoglobin also retained about $95 \%$ of its biological activity and had low molecular mass variability in the final product. The polydispersity index, a measure of molecular mass variability in polymer samples, was 1.4. As the polymer chains approach uniform size, the polydispersity index approaches 1.

Chilkoti noted that they could further reduce this variability by optimizing the reaction conditions or by using an alternative polymerization method. For PEG, the current industry standard is about 1.05 or lower.

"Indiscriminate pegylation of a protein typically results in the formation of heterogeneous protein-polymer conjugates with unacceptably low biological activity," Chilkoti noted in an e-mail to SciBX. "For example, the pegylated interferons (Roferon-A and Intron A) only have less than $10 \%$ of the original protein activity."

poly[OEGMA] also could have an advantage because it has an ester backbone that is biodegradable. The majority of pegylated proteins become unsuitable for renal elimination due to their increased size, and the lack of a renal clearance route can increase drug accumulation and toxicity. ${ }^{3}$ In contrast, a large poly[OEGMA]-protein conjugate would be degraded by the body's esterases, creating smaller pieces that the kidney could clear.

"Chilkoti can go to much bigger polymers with his approach than with pegylation and should be able to achieve much longer circulation times" because the higher the molecular weight of the polymer, the longer the protein's circulation time, Hubbell told SciBX. "This is very important for a very large number of proteins, where reducing injection frequency would make life easier for the patient and smooth the dose profile over time." 
As a next step, Hubbell suggested that Chilkoti conduct "bakeoff experiments, comparing head-to-head the pharmacokinetics of clearance of his approach versus pegylated protein, and to demonstrate that his polymer is cleared from the body."

Hubbell added: "Even if the pharmacokinetics were equivalent, though, his method is potentially better from a synthetic point of view."

\section{On-site complications}

Although the N-terminal poly[OEGMA] conjugation approach described in the PNAS paper should be applicable to most proteins, certain features at a protein's $\mathrm{N}$-terminus site could restrict its applicability.

"N-terminal serine, cysteine, threonine and tryptophan will be incompatible with this method due to known side reactions with aldehydes," Chilkoti told SciBX. "In addition, N-terminal proline will be expected to be unreactive."

However, he said, these limitations "would be solved by using protein engineering to add a compatible amino acid residue at the $\mathrm{N}$ terminus or mutating the $\mathrm{N}$-terminal residue with a compatible amino acid residue."

"The method also may not work when protein-protein interactions at the $\mathrm{N}$-terminus are important for function, for example, with parathyroid hormone," said Hubbell. "But this is not often the case."

Chilkoti said this issue could be resolved by modifying the C-terminal of a protein instead of the $\mathrm{N}$-terminal.

Francesco Veronese, a retired professor from the Department of Pharmaceutical Sciences at the University of Padua who has worked on pegylation for much of his career, was more skeptical about the potential clinical use of poly[OEGMA] conjugation. He noted that conjugation strategies need to minimize the number of reaction steps that involve the protein.

He said the approach described in the PNAS paper "implies two consecutive reactions followed by polymerization on the protein molecule."

Because of these multiple steps, Veronese thinks the conjugation approach also will require additional purification to separate out protein that failed to polymerize and impurities generated from each reaction step. In classical pegylation, he said, a protein only undergoes a single reaction and the compounds that did not react are easy to separate out.

Veronese also wanted to see an evaluation of the immunogenicity. He said an immune response could be elicited by poly[OEGMA] itself, by the impurities that remain following the multiple reaction steps or by changes to the protein.

The answers could come from Chilkoti and his group, which are now applying the N-terminal poly[OEGMA] approach to protein- and peptide-based therapeutics, including cancer and diabetes treatments.

"We expect site-specific poly[OEGMA] conjugation of these therapeutics will not only improve their pharmacokinetics and pharmacodynamics but minimize their systemic toxicity and immunogenicity because of the nontoxic and nonimmunogenic characteristics of the OEG side chains," he told SciBX.

The patent status of the $\mathrm{N}$-terminal poly[OEGMA] conjugation approach described in PNAS is undisclosed. The work is available for licensing from the Duke University Office of Licensing \& Ventures.

Lou, K.-J. SciBX 2(35); doi:10.1038/scibx.2009.1332

Published online Sept. 10, 2009

\section{REFERENCES}

1. Gao, W. et al. Proc. Natl. Acad. Sci. USA; published online Aug. 17, 2009; doi:10.1073/pnas.0904378106

Contact: Ashutosh Chilkoti, Duke University, Durham, N.C. e-mail: chilkoti@duke.edu

2. Gaberc-Porekar, V. et al. Curr. Opin. Drug Discov. Devel. 11, 242-250 (2008)

3. Caliceti, P. \& Veronese, F.M. Drug Deliv. Rev. 55, 1261-1277 (2003)

COMPANIES AND INSTITUTIONS MENTIONED

Duke University, Durham, N.C.

The Swiss Federal Institute of Technology, Lausanne, Switzerland University of Padua, Padua, Italy 